\title{
LA OFERTA TURÍSTICA VINCULADA A LAS ÁREAS DE INFLUENCIA SOCIOECONÓMICA DE LOS PARQUES NACIONALES DE CASTILLA-LA MANCHA: TABLAS DE DAIMIEL Y CABAÑEROS
}

\author{
Óscar Serrano Gil* \\ Ana Eulalia Aparicio Guerrero** \\ Universidad de Castilla-La Mancha
}

\section{RESUMEN}

La declaración de un nuevo Espacio Natural Protegido (ENP) sobre un territorio determinado, especialmente si esa declaración es la mayor figura de protección que recoge la normativa estatal (Parque Nacional), supone, entre otros factores, un revulsivo económico para las Áreas de Influencia Socioeconómica (AIS) en las que se sitúan, llegando a convertirse, en algunos casos, en un complemento a las economías locales dominadas principalmente por la agricultura y la ganadería.

El turismo rural y de naturaleza, aunque no es la panacea universal ni representa la solución definitiva a algunos de los problemas que presenta el mundo rural, se ha convertido, por el valor que puede generar en estos territorios (Daimiel y Cabañeros), en una herramienta indispensable para el desarrollo social y económico de las áreas protegidas.

Palabras clave: Parque Nacional, Área de Influencia Socioeconómica, Cabañeros, Tablas de Daimiel, turismo rural.

Recibido: 14 de diciembre de 2015

Devuelto para su revisión: 25 de abril de 2016

Aceptado: 8 de junio de 2016

* Departamento de Geografía y Ordenación del Territorio. Facultad de Educación. Avda. Carlos III, s/n. 45071 TOLEDO (España). E-mail: Oscar.Serrano@uclm.es

** Departamento de Geografía y Ordenación del Territorio. Facultad Ciencias de la Educación y Humanidades. Avda. de los Alfares, 44. 16071 CUENCA (España).E-Mail: Ana.Aparicio@uclm.es 


\title{
The tourist offer linked to the socio-economic influence areas of the National Parks of Castilla-La Mancha: Tablas de Daimiel and Cabañeros
}

\begin{abstract}
The declaration of a new protected natural area (ENP) on a territory, especially when it declaration is the higher figure of protection by the natural state legislation (National Park) involves an economic push for these socio-economic areas because the new area is made into a complement to support the local economies dominated by cattle and agriculture.

The rural and nature tourism is not a panacea. Also, it does not provide a definitive solution to some problems in the rural world. These types of tourism have become, due to the value they can generate in these territories (Daimiel and Cabañeros), an essential tool for the social and economic development of the protected areas.
\end{abstract}

Keywords: National Park, socio-economic influence area, Cabañeros, Tablas de Daimiel, rural tourism.

\section{INTRODUCCIÓN}

El incremento de la red de Espacios Naturales Protegidos (ENP) en nuestra geografía ha sido un fenómeno que ha proliferado en los últimos treinta años, asociado a la demanda social de protección de los recursos naturales. Sin embargo, este proceso y los limitados avances realizados en la tarea de integrar a las poblaciones locales en la conservación de los espacios, no han conseguido superar la percepción por parte de los residentes de haber sido marginados en la toma de decisiones con respecto a sus territorios debido, en gran parte, a la falta de información.

Buena parte de la población que habita dentro de un espacio natural se siente en desventaja en relación con aquellos que están fuera de sus límites. Esta característica se repite en distintos Parques Nacionales y Naturales y se asocia principalmente a las expectativas del sector urbanístico y de las infraestructuras territoriales. Es importante llevar a cabo una planificación del territorio que no signifique un menoscabo de sus posibilidades de desarrollo local, y sopesar mucho las medidas restrictivas a tomar, haciendo partícipe y co-responsable a la población local (Heras Hernández, 2001).

La conservación de los elementos sobresalientes del área y los valores de biodiversidad del espacio no debe estar reñida con su aprovechamiento desde una óptica de ocio y estética. En este sentido, es crucial activar el paisaje, el clima y los elementos naturales destacables y hacer un uso ordenado de los mismos que permita impulsar la microeconomía local (Antón Clavé, Blay Boqué et al., 2008). Este objetivo daría un doble resultado: por un lado, la configuración de una diversificada estructura económica local, y por otro, una vinculación de la población local en la protección de los recursos naturales y paisajísticos, haciéndoles ver que la mejora de la calidad de vida rural puede depender del mantenimiento de los paisajes y de los valores de biodiversidad de sus comarcas. En este sentido, en los últimos años se ha avanzado bastante en mecanismos y sistemas que compatibilizan 
el uso del espacio para actividades ecoturísticas y el aprovechamiento social. Pero también hay que sopesar que un mal uso turístico de nuestros espacios naturales puede causar un impacto negativo en algunos casos irreversible (Serrano de la Cruz Santos-Olmo, 2002).

Con la regulación protectora de espacios naturales surgirán actividades emergentes que supondrán una modificación de la distribución del poder económico local. La amplitud de los cambios dependerá de la situación inicial en cada caso. Los intereses económicos ligados al uso agrícola y urbano del territorio protegido podrían ver perjudicadas sus expectativas, frente a los intereses ligados a la prestación de servicios a los nuevos flujos de visitantes, que aparecerán como el grupo más favorecido y dinámico de la actividad económica local.

En el supuesto de que el ENP disponga de un entorno habitado, se producirá una revalorización de los productos comerciales locales sobre la base de la demanda in situ de los visitantes. La ampliación de la demanda de productos tradicionales favorecerá la permanencia de actividades agrarias en proceso de extinción. Estas actividades supondrán en sí mismas una oferta de cultura tradicional que incrementará el valor total del espacio protegido (Alba Alonso y Rivas, 1996).

La actividad ligada a la restauración y alojamiento de visitantes exige volúmenes iniciales de fondos financieros probablemente no disponibles en cantidad suficiente por el grupo activo de la población local dispuesto a prestar dichos servicios. Sin embargo, también es cierto que las subvenciones y ayudas de distinto origen han primado este aspecto. Siendo la actividad hotelera la de mayor expansión relativa potencial, es también la más difícil de ejercer a corto plazo por la población local ante las altas exigencias de calidad en la prestación de los servicios que demanda la clase media urbana que afluye a consumir los servicios del espacio rural.

No obstante, conviene recordar que hasta fechas recientes la política de Parques Nacionales, respecto al turismo y su impacto, se ha apoyado en la aplicación de controles y filtros para el desarrollo del ecoturismo o turismo verde. Los Parques Nacionales y Naturales, ya sean de carácter nacional o internacional, se conciben principalmente como instrumentos y entidades de conservación y preservación de la naturaleza, a los que se suman las funciones de investigación y educación y, de forma secundaria, las turísticas y de desarrollo socioeconómico (Vera Rebollo, Palomeque López et al., 1997). Sin embargo, hoy día las autoridades y los gestores de los ENP afrontan el dilema que representa el mantenimiento rígido de su política de conservación ambiental y control de acceso y la promoción turística, por no hablar del imprescindible desarrollo socioeconómico de los territorios en los que se inscriben (Tolón Becerra, 2000), máxime cuando la población y los usos tradicionales han sido clave en su grado de conservación actual.

Los ENP pueden suponer una limitación a las actividades que desarrollan los habitantes de la zona según recoge la normativa de su declaración. Gran parte de las poblaciones que habitan en el interior o áreas de influencia de estos espacios dependen del sector primario, y la incorporación de restricciones de uso no suele ser bien recibida por sus débiles economías. En ocasiones, la gestión del espacio natural se resume en una lista de controles y restricciones, considerándose que los objetivos de conservación y los de estas comunidades son incompatibles. 
Conviene recordar que las poblaciones que residen en ENP tienen la esperanza de que éstos se conviertan en el motor generador de un nuevo desarrollo económico, tanto por medio de las ayudas de las diversas administraciones como por el desarrollo de iniciativas privadas que utilizan como reclamo el propio ENP (AA.VV., 1997a). Por otra parte, es imprescindible tener en cuenta la realidad enunciada por Troitiño (1995) sobre: "las posibilidades reales de los espacios naturales protegidos para funcionar como instrumentos dinamizadores de recursos y promotores de desarrollo rural sustentable, en zonas que actualmente se caracterizan por tener bajos niveles de renta, dinámicas regresivas y relaciones bastante conflictivas entre protección y promoción".

En resumen, los cambios producidos en la demanda turística y la necesidad de los propios territorios de diversificar su estructura productiva, mejorando las oportunidades para la generación de empleo y de riqueza para la población rural, han convertido al turismo de naturaleza y al turismo rural en un instrumento de primera magnitud para el desarrollo socioeconómico de la mayor parte de los ENP (Pulido Fernández, 2007a, 2007b, 2008, Puertas Cañaveral, 2008). Es necesario, por tanto, afrontar una nueva etapa, caracterizada por un enfoque proactivo en el tratamiento del turismo por parte de los gestores de espacios naturales, haciendo posible el binomio conservación desarrollo. Sin embargo, para ello es necesaria la confluencia de varias circunstancias. Primero, que estos gestores (directores-conservadores, órganos de gobierno y de gestión, etc.) asuman los valores del turismo como instrumento al servicio del desarrollo y de la conservación de estos espacios (Fernández Tabales y Santos Pavón, 2010). Y, segundo, que se disponga de especialistas en turismo que asuman esta gestión. En cualquier caso, la aplicación de técnicas de diseño de productos propias de la gestión de destinos turísticos puede permitir conservar sus recursos ambientales, poner en valor sus atributos y dotar al espacio natural de competitividad territorial (Antón Clavé, Blay Boqué et al., 2008).

\section{OBJETIVOS Y METODOLOGÍA}

Las dos comarcas que se presentan en la investigación, el Área de Influencia Socioeconómica del Parque Nacional de las Tablas de Daimiel y el Área de Influencia Socioeconómica del Parque Nacional de Cabañeros, responden a dos perfiles socioeconómicos bien diferenciados. Partimos de la escala de estudio del Área de Influencia Socioeconómica (AIS) que, tomando la definición que la normativa estatal y que posteriormente cada una de las Comunidades Autónomas hizo suya, correspondería con el conjunto de los términos municipales en cuyo territorio se encuentra situada alguna porción del ENP o de sus Zonas Periféricas de Protección (ZPP) (Jefatura del Estado, 1982: art.1).

Atendiendo a esta definición, se puede considerar, en el caso del Parque Nacional de las Tablas de Daimiel, que su AIS estaría compuesta básicamente por los municipios afectados por este espacio natural, dos municipios de la provincia de Ciudad Real (Daimiel y Villarrubia de los Ojos), aunque en la ZPP habría que incluir al menos las 30 ha. pertenecientes al término municipal de Torralba de Calatrava (cuadro 1, figura 1). 
No obstante, y en aras de los cambios normativos que ha sufrido el espacio protegido, la ley de reclasificación del Parque -ley 25/1980, de 3 de mayo- establecía que el AIS estaba compuesta por un conjunto más amplio de municipios ${ }^{1}$.

\section{Cuadro 1 \\ DATOS BÁSICOS DEL PARQUE NACIONAL DE LAS TABLAS DE DAIMIEL}

\begin{tabular}{|c|c|c|c|}
\hline Superficie (ha.) & & & $3.030,5$ ha. \\
\hline $\begin{array}{l}\text { Superficie de la zona de } \\
\text { protección }\end{array}$ & & & $5.410,0$ ha. \\
\hline \multirow{2}{*}{ Titularidad de los terrenos } & Público (Estatal) & & $97,45 \%$ \\
\hline & Privado & & $2,55 \%$ \\
\hline Redes supranacionales & & \multicolumn{2}{|c|}{$\begin{array}{l}\text { LIC y ZEPA } \\
\text { Reserva de la Biosfera } \\
\text { Humedal de Importancia Internacional (Ramsar) }\end{array}$} \\
\hline \multicolumn{4}{|c|}{ Superficie } \\
\hline $\begin{array}{l}\text { Área de Influencia } \\
\text { Socioeconómica } \\
\text { (AIS) }\end{array}$ & $\begin{array}{l}\text { Superficie } \\
\text { (término } \\
\text { municipal) (ha.) }\end{array}$ & $\begin{array}{l}\text { En el Parque Nacional } \\
\text { (ha.) }\end{array}$ & En la ZPP (ha.) \\
\hline Daimiel (CR) & 43.830 & 1.582 & 3.812 \\
\hline Villarrubia (CR) & 28.186 & 346 & 1.568 \\
\hline Torralba de Calatrava (CR) & 10.158 & - & 30 \\
\hline Total & 82.174 & $1.928^{2}$ & 5.410 \\
\hline
\end{tabular}

Fuente: Ministerio de Medio Ambiente y Medio Rural y Marino, 2008a y 2008b. Elaboración propia.

En el caso del Parque Nacional de Cabañeros, su AIS, según recoge la norma de declaración -ley 33/1995, de 20 de noviembre- (Jefatura del Estado, 1995), la componen seis municipios, cuatro de ellos pertenecientes a la provincia de Ciudad Real (Alcoba, Navas de Estena, Horcajo de los Montes y Retuerta del Bullaque) y dos a la de Toledo (Hontanar y Los Navalucillos) (cuadro 2, figura 2). En esencia, responden a dos comarcas y dos territorios con factores demográficos, sociales y económicos muy dispares en donde el impulso del ENP se ha ido percibiendo como un complemento cada vez más necesario de las rentas locales.

1 En esa fecha, el AIS estaba compuesto por los términos municipales de: Daimiel, Villarrubia de los Ojos, Torralba de Calatrava, Manzanares, Carrión de Calatrava, Bolaños de Calatrava y Llanos del Caudillo.

2 Todavía en la actualidad (abril de 2016) el Organismo Autónomo de Parques Nacionales mantiene en su base de datos los relativos a la superficie de cada término municipal dentro del Parque previos a la ampliación de enero de 2014, aunque la ampliación supone contar con una superficie de 3.030 ha. de Parque Nacional. 


\section{Figura 1 \\ MAPA DE SITUACIÓN DEL ÁREA DE INFLUENCIA SOCIOECONÓMICA DEL PARQUE NACIONAL DE LAS TABLAS DE DAIMIEL}

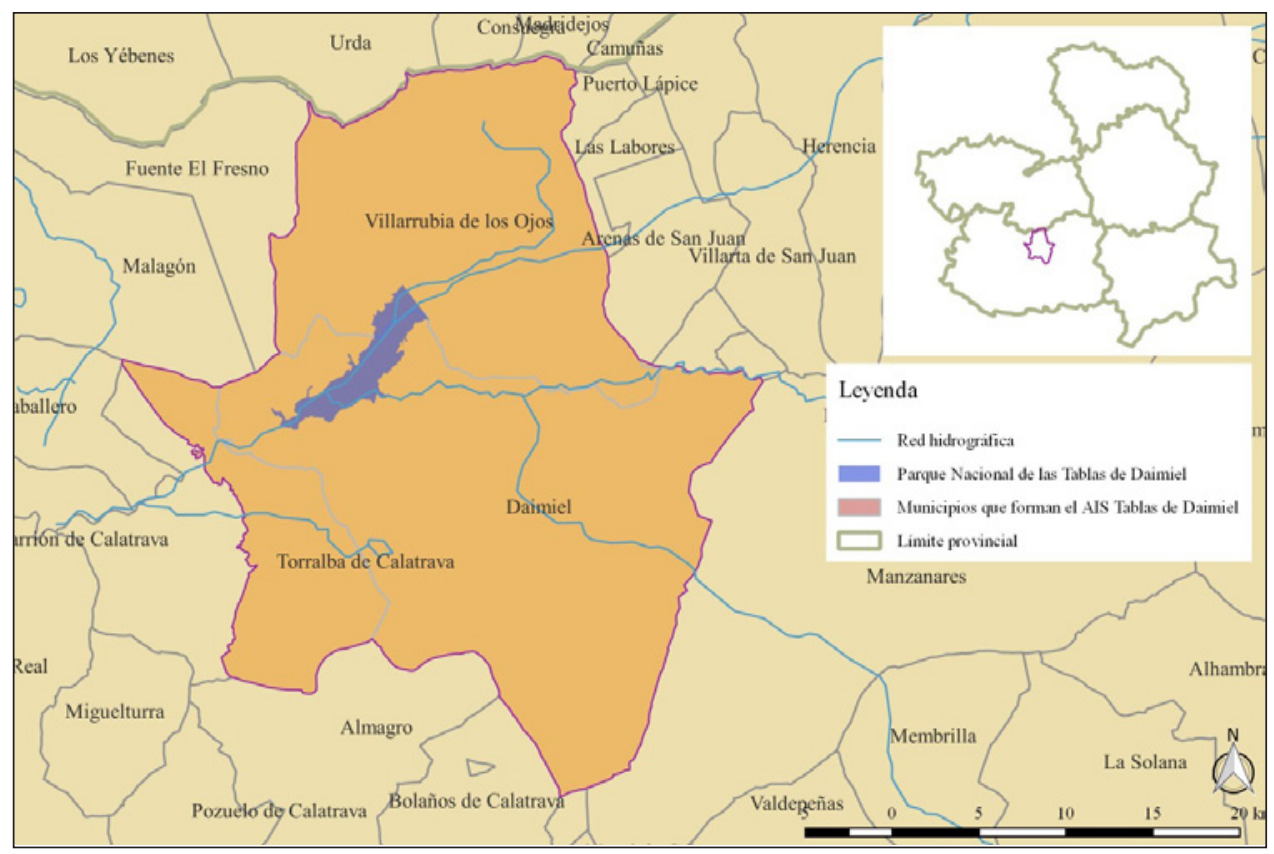

Fuente: Ministerio de Medio Ambiente y Medio Rural y Marino y Red de Parques Nacionales. Elaboración propia.

Este territorio ofrece destacados elementos patrimoniales considerados de interés turístico, sobre todo en un momento en el que los turismos de interior se van convirtiendo en una auténtica alternativa de desarrollo económico en el seno de una política de desarrollo local. Apoyado en el reclamo que supone contar con un Parque Nacional en su comarca, el turismo rural y cultural no deja de ser una herramienta clave y esencial para el desarrollo social y económico de estas AIS. Con el presente trabajo hemos analizado los principales elementos patrimoniales tanto naturales como culturales, considerados de interés turístico y que en aras de la puesta en marcha de políticas de desarrollo local pueden considerarse piezas clave en el diseño de alternativas de desarrollo económico que complementen las rentas de sus habitantes, para después llevar a cabo un estudio comparativo de la oferta básica de alojamiento y de restauración complementaria en cada una de estas dos comarcas.

Desde el punto de vista de las fuentes y la metodología, después de realizar una exhaustiva y necesaria búsqueda bibliográfica (Coronado, León et al., 1974; Rodriguez, 1986; Carrasco Redondo, 2001; De la Beldad Caro, Serrano Menchén et al., 2007, ...) y de consultar diversas guías de restaurantes y alojamientos de los municipios de las AIS (AA.VV., 1997b; AA.VV., 2009, ...) hemos examinado la información proporcionada en portales especializados en reservas y en las principales páginas webs de las administraciones locales, provinciales y regionales así como de Grupos de Desarrollo Rural. 


\section{Cuadro 2 \\ DATOS BÁSICOS DEL PARQUE NACIONAL DE CABAÑEROS}

\begin{tabular}{|c|c|c|}
\hline Superficie (ha.) & \multicolumn{2}{|c|}{$40.856,22$} \\
\hline \multirow{2}{*}{$\begin{array}{l}\text { Titularidad de los } \\
\text { terrenos }\end{array}$} & $55,65(\%)$ & $22.721,41 \mathrm{ha}^{3}$ \\
\hline & $44,35(\%)$ & $18.107,26 \mathrm{ha}^{4}$ \\
\hline Redes supranacionales & \multicolumn{2}{|c|}{$\begin{array}{l}\text { LIC y ZEPA } \\
\text { Superficie }\end{array}$} \\
\hline Área de Influencia Socioeconómica & $\begin{array}{l}\text { Superficie en la AIS } \\
\text { (término municipal ha.) }\end{array}$ & $\begin{array}{c}\text { En el Parque Nacional } \\
\text { (ha.) }\end{array}$ \\
\hline Alcoba (CR) & 30.710 & $15.527,5$ \\
\hline Navas de Estena (CR) & 20.844 & $9.747,5$ \\
\hline Horcajo de los Montes (CR) & 14.654 & $6.135,5$ \\
\hline Retuerta del Bullaque (CR) & 65.390 & 3.743 \\
\hline Hontanar (TO) & 15.177 & $3.055,7$ \\
\hline Los Navalucillos (TO) & 35.594 & $2.643,8$ \\
\hline Total & 182.369 & $40.837,40^{5}$ \\
\hline
\end{tabular}

Fuente: Ministerio de Medio Ambiente y Medio Rural y Marino, 2008a y 2008b. Elaboración propia.

Figura 2

MAPA DE SITUACIÓN DEL AIS PARQUE NACIONAL DE CABAÑEROS

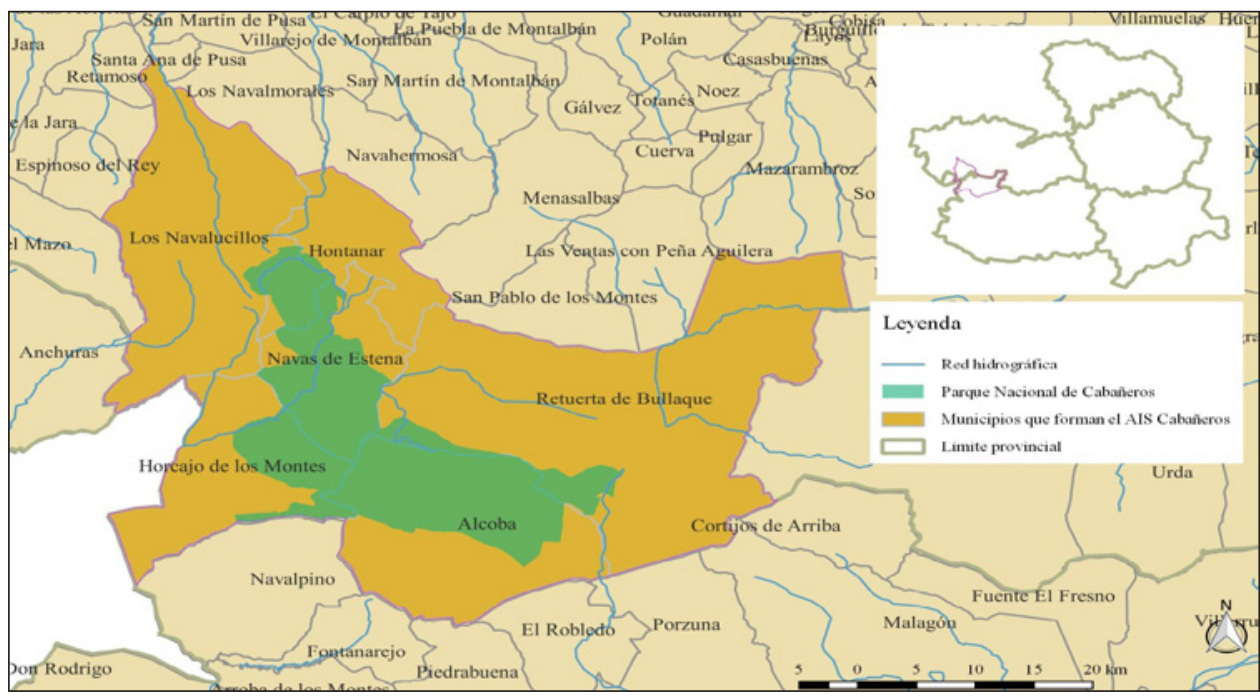

Fuente: Ministerio de Medio Ambiente y Medio Rural y Marino y Red de Paques Nacionales. Elaboración propia.

3 Hay tres fincas de monte público: El Chorro (Los Navalucillos), Sierra de Castellar de los Bueyes (Horcajo de los Montes) y Fuente del Caño y Sierra del Ramiro (Navas de Estena) que suman 2.929 ha. (Ministerio de Agricultura, Alimentación y Medio Ambiente, 2011: 105-106).

4 Esta superficie se reparte entre 15 propietarios. Destacan, en superficie, la finca de Cabañeros con 6.319 ha., y Los Acebuches con sólo 377 ha.

5 A este total habría que añadir 18,82 ha. pertenecientes al término municipal de Navalpino (Ciudad Real). 


\section{EL PARQUE NACIONAL DE LAS TABLAS DE DAIMIEL Y EL PARQUE NACIO- NAL DE CABAÑEROS: DOS ESPACIOS NATURALES PROTEGIOS MUY CONTRASTADOS DESDE EL PUNTO DE VISTA NATURAL Y CULTURAL}

Desde el punto de vista geomorfológico, la llanura manchega es una cuenca sedimentaria formada por la orogenia alpina y colmatada con sedimentos detríticos (conglomerados y areniscas) en la base y químicos en los tramos superiores (yesos y calizas), cubiertos por mantos aluviales y depósitos eólicos del Cuaternario. Su topografía plana se explica, en parte, por la existencia de unas superficies de erosión modeladas a finales del Terciario y en el Plioceno, y por la incapacidad del río Guadiana y sus afluentes para encajarse en estos materiales. Por otro lado, la planitud del territorio ha producido unos fenómenos endorreicos muy interesantes, con la presencia de charcas estacionales y lagunas, algunas de ellas salobres.

En este vasto territorio, la red de ENP presenta una numerosa variedad de declaraciones. Indudablemente el espacio de mayor notoriedad desde el punto de vista turístico es el Parque Nacional de las Tablas de Daimiel, que en enero de 2014 sufrió una ampliación de más de 1.000 ha. (Ministerio de Agricultura, Alimentación y Medio Ambiente, 2014a) llegando a superar las 3.000 ha.

Los indudables méritos de este espacio justifican que fuera incluido, junto con otros humedales interiores de La Mancha, en la Reserva de la Biosfera conocida como la "Mancha Húmeda" en el año 1981 y, posteriormente, como humedal vinculado al convenio Ramsar en 1982. Inicialmente planificada sobre unas 25.000 ha., la constante degradación de la misma, su dispersión geográfica sin delimitación específica y su inoperancia proteccionista generaron un movimiento de carácter social que llegaría a plantearse su posible desclasificación en 2008. Esta situación condujo a una nueva propuesta que englobaría una ampliación de unas 294.321 ha. en diferentes zonas: núcleo, tampón y transición (Peinado Martín-Montalvo y Plaza Tabasco, 2011; Ruiz Pulpón, et al., 2010). Sin embargo, no será hasta junio de 2014, cuando el Consejo Internacional de Coordinación de Programa de la Unesco sobre el Hombre y la Biosfera $(\mathrm{MaB})$ acordó la ampliación de la inicial Reserva de la Biosfera de la "Mancha Húmeda" hasta las 418.087 hectáreas 6 acogiendo en su interior 76 lagunas y zonas de dominio público hidráulico de treinta y tres cauces fluviales (Ministerio de Agricultura, Alimentación y Medio Ambiente, 2014b).

El resto de los ENP que se vinculan a los municipios del AIS vienen a reforzar la riqueza y diversidad de ecosistemas de humedales continentales, con gran riqueza de avifauna. De cara a la elaboración del producto "turismo ornitológico", su potencial es enorme y en buena medida sin explotar. Por último, La Mancha atesora distintos espacios integrados dentro de la Red Natura 2000 de la Unión Europea. Así, entre las Zonas Especiales para la Protección de las Aves (ZEPAs) destacan el área esteparia de La Mancha y el área esteparia del campo de Montiel. Respecto a los Lugares de Importancia Comunitaria (LICs), destaca las Lagunas de Ruidera; y finalmente, encontramos espacios que contienen ambas declaraciones (ZEPAs y LICs): los Humedales de La Mancha, los Montes de Toledo y las Tablas de Daimiel. En total se protegen más de 350.000 ha. de ZEPAs y casi unas 270.000 ha. de LICs.

6 "La Mancha Húmeda amplía su protección”, ABC.es, 21/06/2014, disponible en: http://www.abc.es/ toledo/ciudad/20140615/abci-mancha-humeda-amplia-proteccion-201406151738.html. La aprobación definitiva, que incluye las 418.087 ha. se hizo efectiva en noviembre de 2014. 
Siguiendo a Valenzuela Rubio (1997:13), es necesario "un nuevo modelo de territorio turístico en que se aúne el máximo de satisfacción para el turista con el máximo de beneficio para la población y el área que lo acoge". La riqueza histórica, cultural y natural de esta llanura manchega posibilita e induce a su conocimiento, combinando turismo patrimonial, medioambiental y rural en un momento en el que la multifuncionalidad y diversificación de las actividades agrarias están a la orden del día. Este proceso podría animarse con la concesión de la categoría de Patrimonio de la Humanidad, por parte de la UNESCO, a la ruta de Don Quijote ${ }^{7}$, tras ser declarada Itinerario Cultural Europeo por el Consejo de Europa en 2007 (Cañizares Ruiz, 2008), así como por la presencia de importantes humedales con distintos niveles de protección (las Tablas de Daimiel, lagunas de Ruidera, complejos lagunares, etc.) (Jerez García, 2010; Peinado Martín-Montalvo y Plaza Tabasco, 2011).

En el caso de Cabañeros y en relación con sus recursos naturales, este espacio se inscribe dentro de los Montes de Toledo, entre el límite occidental de la llanura manchega y la frontera administrativa con Extremadura. Su relieve, montañoso y de mediana altitud debido a la presencia de pequeños macizos y algunas sierras compuestas de un roquedo muy antiguo, propio de la era Arcaica y Primaria, está integrado por capas de pizarras y cuarcitas sin apenas recubrimientos de materiales sedimentarios de eras más recientes. Desde el punto de vista de su morfología, responden a un tipo de relieve "apalachense" caracterizado por la sucesión de alineaciones cuarcíticas de similar altitud y "surcos" excavados en las franjas de las pizarras. Entre las formas de modelado destaca un elemento propio y característico del paisaje: las "rañas", que son planicies pedregosas al pie de estos relieves montañosos. Además, hay que destacar la presencia de crestas o "agujas" cuarcíticas agudas y astilladas, y las pedrizas o "lanchares", que son el resultado de las fragmentaciones y roturas de estas crestas cuarcíticas.

En el territorio encontramos las llamadas Áreas Críticas, las Zonas de Dispersión y las Zonas de Importancia de Especies como el águila imperial ibérica, el lince ibérico, el buitre negro y la cigüeña negra. El resto de los ENP refuerzan la riqueza y diversidad de los ecosistemas, con gran riqueza de avifauna. La normativa supranacional en materia de protección de la naturaleza también se hace eco de un buen número de LIC y ZEPA, destacando los LIC de las Lagunas de Alcoba y Horcajo de los Montes, los bonales ${ }^{8}$ situados al oeste de la provincia de Ciudad Real, y el alcornocal del Zumajo. Así, además del LIC y ZEPA Montes de Toledo también destaca el de los Ríos de la Cuenca Media del Guadiana y Laderas Vertientes. La enorme riqueza de recursos territoriales turísticos del medio natural la convierte en un potencial destino vinculado al "turismo ornitológico". Los distintos espacios integrados dentro de la Red Natura 2000 suponen más de 250.000 ha. protegidas tanto bajo las figuras de LIC como de ZEPA. El elenco de figuras de protección se completa con un paisaje protegido en el municipio de Horcajo de los Montes (la cho-

7 Con motivo del IV Centenario de la publicación de la primera parte de la novela de El Ingenioso Hidalgo don Quijote de La Mancha, el entonces gobierno regional trazó el corredor ecoturístico más largo de Europa: la "Ruta de don Quijote". Una ruta que aspira a ser catalogada como Patrimonio de la Humanidad por los valores culturales y medioambientales que encierra ofreciendo al viajero la posibilidad de recorrer esos parajes quijotescos.

8 También llamados bohonales o trampales. Son lugares con humedad permanente o casi permanente en donde el agua empapa el terreno o circula muy lentamente por la superficie formando pozas (AA. VV, 2003: 4) 
rrerra de Hocajo), una reserva fluvial en Retuerta del Bullaque (Sotos del río Milagro) y un refugio de fauna en el municipio de Los Navalucillos (la nava de Don Diego).

Respecto al patrimonio cultural, las diferencias entre comarcas también son notorias. En Daimiel, la comarca de La Mancha cuenta con un destacable patrimonio cultural como lo demuestra el número de Bienes de Interés Cultural ${ }^{9}$ (BIC) (43). Realizando un análisis en detalle, la categoría de monumentos adquiere un mayor peso representando un $93,02 \%$ del total de los que 22 son monumentos religiosos $(51,16 \%)$ y 18 civiles $(41,86 \%)$. También encontramos algunos sitios históricos (Molinos de viento "Cerro de la Paz y Sierra de los Molinos" en Campo de Criptana) y zonas arqueológicas (Yacimiento arqueológico Cerro de las Cabezas en Valdepeñas). Por municipios, Alcázar de San Juan (7 BICs) representa un 16,28 \% sobre el total, seguido de Campo de Criptana con 6 BICs declarados $(13,95 \%)$ y Daimiel y Valdepeñas $(11,63 \%)$ con 5 BICs cada uno. El resto de municipios suman entre uno y tres BICs respectivamente. Por tanto, el AIS de las Tablas de Daimiel, contaría con 5 BICs del conjunto total de la comarca de La Mancha.

La gastronomía, debido en parte a la potenciación desarrollada por los distintos marchamos de calidad (especialmente varias Denominación de Origen Protegida -D.O.P.- y alguna Indicación Geográfica Protegida -I.G.P.-) vinculados a productos como el vino, el queso, el aceite, el azafrán, el cordero, la cebolla, el melón y el pan, entre otros, representa un recurso novedoso que progresivamente se va convirtiendo en una herramienta de dinamización turística de la comarca de Daimiel. Esto supone la existencia de una marca de calidad que favorece el desarrollo del turismo gastronómico aumentando la especialización y la mejora de la oferta turística de la comarca. El producto turístico más desarrollado ha sido, sin duda, el enológico. Este tipo de turismo se presenta como una incipiente alternativa vacacional y de desarrollo económico. Las actividades de las bodegas incluyen alojamiento, cursos de cata, restaurante, rutas, visita degustación, visita al viñedo y tienda, así como actividades complementarias de turismo activo y paquetes especiales para empresas. Sirva de ejemplo, la Asociación Turismo Enológico de Castilla-La Mancha Divinum Vitae que aglutina 30 bodegas cuya finalidad principal es la promoción del turismo relacionado con el vino, estando representada en la comarca de Daimiel por 7 bodegas ${ }^{10}$.

El AIS de Cabañeros también posee elementos de patrimonio cultural aunque no encontramos ni un solo Bien de Interés Cultural (BIC) en toda la comarca. En cuanto al patrimonio arqueológico, destacan los grabados rupestres (Navalpino, Arroba de los Montes y Anchuras) de la edad del Bronce y anteriores (Ministerio de Agricultura, Alimentación y Medio Ambiente, 2010). Además, la romanización llegó al territorio a tra-

9 La declaración legal denominada Bien de Interés Cultural (BIC) es una figura de protección de los bienes culturales en España, establecida por Ministerio de Cultura en la Ley 16/1985, de 25 de junio, del Patrimonio Histórico Español. Posteriormente esta figura de máximo rango fue asumida paulatinamente por la legislación de las Comunidades Autónomas, entidades que participan en la incoación de expedientes y estudios, con la supervisión del Ministerio de Cultura para la declaración definitiva.

10 Las siete bodegas pertenecientes a la red son: Bodegas Viñasoro (Alcázar de San Juan), Bodegas Montalvo Wilmot (Argamasilla de Alba), Bodegas y viñedos Castilblanque (Campo de Criptana), Bodegas Lahoz (Socuéllamos), Bodegas Finca Los Nevados (Socuéllamos), Bodegas Dionisos (Valdepeñas) y Bodegas Real (Valdepeñas). 
vés de una vía romana que atraviesa el Parque Nacional en dirección noroeste-suroeste uniendo Toledo y Mérida (Caballero Klink, 1997). También existen restos de necrópolis visigodas denominadas "lucillos" (sepulcros) en Los Navalucillos y la necrópolis visigoda del paraje El Rodeo de Navas de Estena. De época medieval, destaca el enclave estratégico y defensivo de la Torre de Abraham, en Retuerta del Bullaque.

A todo esto hay que unir la existencia de museos interesantes dentro del AIS de Cabañeros. Destaca el museo etnográfico de Horcajo de los Montes, de titularidad municipal, con una amplia colección de útiles y herramientas propias de la vida tradicional agrícola y ganadera de la comarca; el museo etnográfico de Alcoba que, igualmente, concentra utensilios representativos del modo de vida tradicional de los hombres y mujeres de esta comarca; y el molino del Brezoso que cuenta con maquinaria en uso y una exposición en su interior (Ministerio de Agricultura, Alimentación y Medio Ambiente, 2010). A ello se añaden las distintas sendas o itinerarios etnográficos de los que informa el centro de visitantes de Casa Palillos (Alcoba) y que se completan con paneles informativos sobre la cultura ganadera y agrícola del territorio.

\section{FRECUENTACIÓN E INFRAESTRUCTURAS TURÍSTICAS DE LAS ÁREAS DE INFLUENCIA SOCIOECONÓMICA}

Como señalan algunos autores, el estudio de la frecuentación turística en los ENP españoles es una asignatura pendiente (Muñoz Flores, 2008). En general, el conocimiento es muy fragmentado, falto de continuidad en el tiempo, impreciso (raramente distingue entre visitantes, que no pernoctan en el área, y turistas, que sí lo hacen) e insuficiente para conocer con detalle cuántos visitantes reciben los ENP y cuál es su perfil. No obstante, los datos disponibles apuntan que el turismo de naturaleza se está consolidando.

Según el Anuario EUROPARC-España del estado de los ENP para el año 2005, cada año acudían una media de 49,4 millones de personas a los ENP españoles en una estimación a la baja. Sólo el 16,85 \% de los visitantes que accedían a los Parques Nacionales utilizaban los centros de visitantes, con un promedio de 31.400 visitas anuales por centro. Según los datos aportados por el Organismo Autónomo de Parques Nacionales para diversos años $(2007,2013)$, de la cifra total de visitantes los tres Parques Nacionales que presentan los datos más elevados de turistas y visitantes son: Teide, Picos de Europa y Timanfaya. En claro contraste, los de menor frecuentación turística son: el archipiélago de Cabrera y Cabañeros. La cifra de los 10 millones de visitas se mantiene prácticamente constante desde 2007, con alguna ligera bajada en torno a los 9,5 millones durante los años centrales de la actual crisis económica (años 2010 y 2012).

En este contexto, el Parque Nacional de las Tablas de Daimiel se sitúa en la actualidad en el duodécimo puesto por número de visitas entre los quince parques nacionales. No obstante, la cifra no refleja la realidad, pues al ser un espacio de acceso libre, sin restricción alguna en el número de visitantes ni de horarios, los datos sólo recogen aquéllos que pasan por el centro de interpretación situado a la entrada del parque durante su horario de apertura al público. Los graves problemas que tiene planteados el Parque en los últimos tiempos, y que se reflejan en las 
oscilaciones que experimenta en el número de visitantes que ha recibido son de sobra conocidos (falta de agua por presión agrícola, períodos de sequía, etc.). Estas dificultades, acentuadas en determinados años, no han dejado de pasar factura a sus posibilidades de atracción/fidelización de determinado tipo de visitantes/turistas.

Respecto a la afluencia de visitantes al Parque Nacional, las cifras hasta el año 2009 oscilaron entre 100.000 y los 130.000 visitantes por año (figura 3), siempre condicionadas por períodos de sequía (años 2006 y 2009). El incremento puntual del año 2010 desciende a partir de esta misma fecha retomando valores similares a la tendencia generalizada de años precedentes (2003-2009).

\section{Figura 3 \\ TOTAL DE VISITANTES. \\ PARQUE NACIONAL DE LAS TABLAS DE DAIMIEL (2003-2013)}

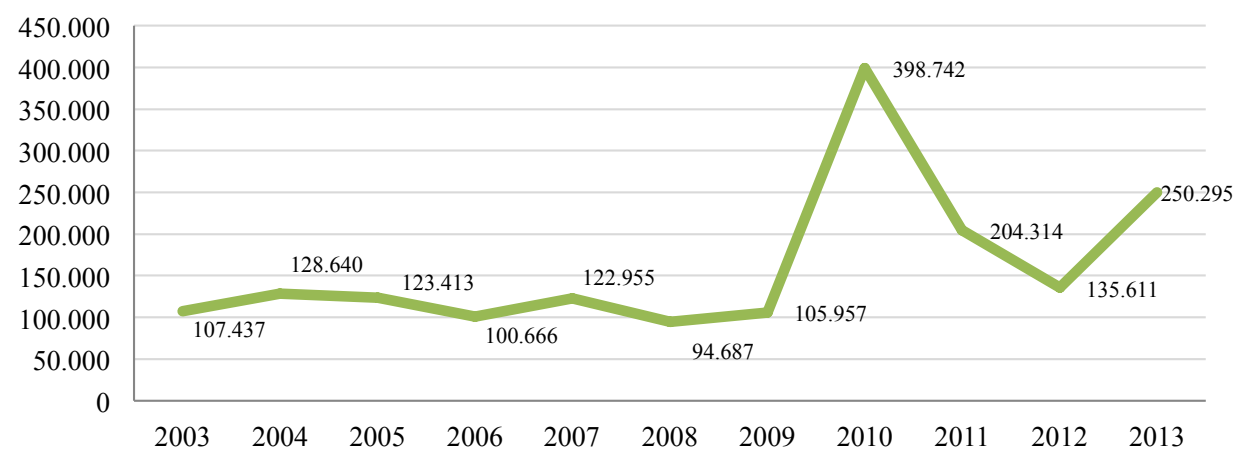

Fuente: Ministerio de Agricultura, Alimentación y Medio Ambiente. Elaboración propia.

A escala comarcal, La Mancha, donde se sitúa el AIS del Parque Nacional de las Tablas de Daimiel, aparece como un destino de interior joven y tímidamente emergente que en los últimos años ha ido mostrando un incremento continuado de viajeros y de ingresos, favorecido por varios factores como el cambio en las preferencias de la demanda, el fuerte apoyo de las acciones institucionales para la creación de infraestructuras y equipamientos, la creación y promoción de destinos, y el progresivo mejor conocimiento de los recursos turísticos comarcales. Las distintas modalidades de turismo presentes en la zona (rural, cultural, deportivo, ecoturismo, cinegético, termal, enológico, etc.) tienen en los conjuntos históricos (Almagro, Villanueva de los Infantes, etc.) y en la naturaleza los soportes territoriales para su práctica.

Respecto al territorio que ocupa el Parque Nacional de Cabañeros, se caracteriza por ser un destino de interior asociado a la presencia de un ENP que le aporta identidad. Así pues, al amparo de esta figura de protección se han ido gestando diversos productos turísticos relacionados con la gastronomía que tratan de complementar el producto de turismo de naturaleza, motivo principal de la mayor parte de los desplazamientos. Son pocos los productos turísticos presentes (rural, cultural, deportivo, ecoturismo, cinegético, etc.) en el territorio comarcal, pero casi todos ellos encuentran en la naturaleza el soporte territorial para su práctica. 
En cuanto a la presión turística en el espacio, se percibe un aumento considerable y sostenido (desde 1995, año de la declaración) en la evolución de las visitas al ENP (figura 4). En líneas generales, y en una visión retrospectiva de la afluencia de visitantes, se puede decir que la tendencia ha sido creciente a pesar de los altibajos. Durante los dos primeros años (1996-1997), la afluencia de visitantes fue relativamente baja, pero su frecuentación fue incrementándose en los primeros del presente siglo. En el año 1998 hubo más de 50.000 visitas y en el 2004 se superaron las 70.000 visitas anuales. Esto indica que, de manera progresiva, la tendencia generalizada en Cabañeros ha sido el crecimiento constante en el número de visitas, a pesar de las limitaciones y restricciones que el ENP sufre a la hora de canalizar los flujos (se trata del Parque Nacional con la relación más baja de visitantes por hectárea y año de toda la red española $-1,9$ visitante por hectárea-), uno de los principales motivos de conflicto entre la dirección del parque y los agentes implicados en el turismo rural de la zona (propietarios de alojamientos, empresarios turísticos, etc.).

A partir del año 2007 continúa la tendencia alcista superándose los 78.000 visitantes en el año 2008. Esa línea de ascenso se ha mantenido especialmente durante 2010 y 2011 cuando el salto ha sido más apreciable superando los 90.000 visitantes y alcanzando su techo en el año 2011 (92.578 visitantes). A partir de esa fecha, ha habido un retroceso significativo pero ralentizado, situándose en valores que oscilan entre las 82.000-85.000 visitas al año. A pesar de esta trayectoria de incremento, desde 2003 a 2013, han visitado el Parque Nacional 870.000 personas, cifra realmente baja si consideramos su extensión.

\section{Figura 4 \\ EVOLUCIÓN DEL NÚMERO DE VISITANTES \\ AL PARQUE NACIONAL DE CABAÑEROS (1996-2013)}

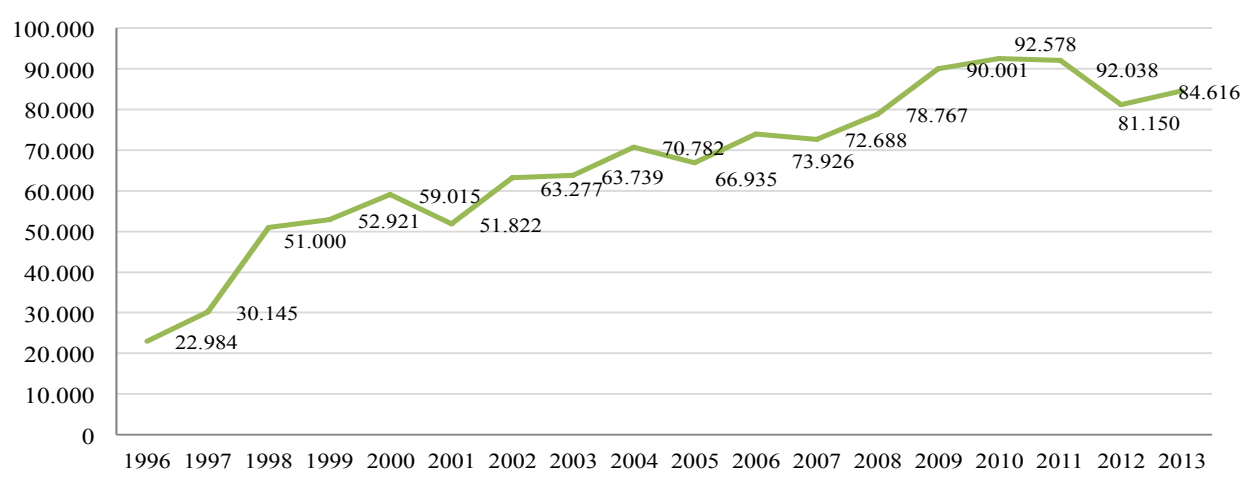

Fuente: Ministerio de Agricultura, Alimentación y Medio Ambiente. Elaboración propia.

En cualquier caso, estos datos no han dejado de ser contestados por los agentes locales de la zona. En mayo de 2014, los empresarios turísticos de Cabañeros denunciaban ante los medios de comunicación que las cifras que el parque había venido manejando y trasla- 
dando a la sociedad no eran las verdaderas, "siendo el número real -según datos oficiales del propio parque- en torno a los 20.000 visitantes al año, cifra muy inferior a los 90.000 visitantes que el Parque Nacional viene facilitando año tras año, desinformando a todos los ciudadanos de manera torticera e interesada" ${ }^{11}$.

A finales de 2009, el Parque Nacional de Cabañeros suscribió la Carta Europea de Turismo Sostenible (CETS), una iniciativa que persigue avanzar de manera efectiva en los principios del turismo sostenible en los ENP buscando una estrecha relación entre el sector turístico y el ENP (Prats Santaflorentina, 2005) mediante la colaboración y la implicación de los principales actores sociales (De la Rosa Guillón, 2005), concediendo una acreditación a aquellos empresarios que hubieran asumido un compromiso para cumplir este objetivo (cuatro empresas de turismo activo y ocho alojamientos rurales) ${ }^{12}$. La carta es un instrumento de planificación participada del turismo sostenible con todos los agentes implicados en el territorio buscando niveles de cooperación institucional entre los departamentos de medio ambiente y turismo (Blanco Portillo, 2005). A fecha de abril de 2016, se ha aprobado la renovación de la CETS que establece un conjunto de medidas para ejecutar tanto por entidades públicas como privadas ${ }^{13}$.

\subsection{La oferta básica de alojamiento extrahotelero en las Áreas de Influencia Socioeco- nómicas analizadas}

Para conocer la oferta de alojamientos hoteleros y extrahoteleros en las AIS, de restauración, así como de establecimientos y servicios al turismo, se han consultado diversas páginas web especializadas. En el caso de Daimiel se han analizado los portales de infoshotal, toprural, tripadvisor, buscorestaurantes, de las administraciones locales de la comarca así como de otras administraciones (dipucr, infomancha, turismodecastillalamancha, etc.) y páginas webs especializadas en el turismo de la comarca (destinosmanchegos, entreparques, tierradecaballeros, lastablasdedaimiel). En el caso de Cabañeros, se han consultado recursos web similares a los utilizados en el caso de Daimiel (entreparques, dipucr, tierrasdecaballeros, turismodecastillalamancha, toprural, tripadvisor, destinosmanchegos y buscoresturantes, entre otros).

En la categoría de alojamientos turísticos extrahoteleros, encontramos cuatro casas rurales en los tres municipios analizados (Daimiel, Villarrubia de los Ojos y Torralba de Calatrava) que suman un total de 46 plazas. Existe, además, un albergue juvenil y un complejo turístico de cabañas rurales/bungalós cuya clientela potencial está directamente vinculada con la presencia del parque (cuadro 3). El albergue juvenil "Tablas de Daimiel" con capacidad para 68 personas se ubica en el centro urbano de Daimiel, frente al Centro de Interpretación del Agua y los Humedales Manchegos, y se dirige a una demanda que de forma organizada (colegios, institutos, asociaciones) o individual visita el ecosistema

11 http://www.abc.es/comunidad-castillalamancha/20140507/abcp-empresarios-cabaneros-criticangestion-20140507.html

12 http://www.magrama.gob.es

13 http://www.latribunadeciudadreal.es/noticia/ZD35D5A8F-CF43-3FA7-C26771DC46169E8F /20160225/plan/accion/turismo/propone/52/medidas/13/millones/inversion/inicial/entorno/caba\%C3\%B1eros 
de las Tablas; por su parte el complejo turístico de "El Mirador de la Mancha" emplazado en Villarrubia de los Ojos cuenta con cabañas, bungalós y otras instalaciones con capacidad para 65 personas. Estas instalaciones constituyen la oferta de alojamiento turístico rural del AIS: seis instalaciones que albergarían casi 180 personas. Se deduce de estos datos, que el alojamiento rural dista mucho de haber alcanzado su techo de desarrollo en la comarca mientras que, por el contrario, la oferta de alojamiento hotelero clásico (hoteles, hostales y pensiones) se encuentra mejor representada, pero vinculada a una clientela tradicional de negocios y de paso.

\section{Cuadro 3}

\section{INFRAESTRUCTURAS DE ALOJAMIENTO EXTRAHOTELERO EN EL AIS DEL PARQUE NACIONAL DE LAS TABLAS DE DAIMIEL (2016)}

\begin{tabular}{|l|r|r|}
\hline & Total alojamientos & Total plazas \\
\hline CR alquiler completo (CA) & 2 & 18 \\
\hline CR alquiler compartido (AC) & 2 & 28 \\
\hline Albergue Juvenil & 1 & 68 \\
\hline Complejo turístico de cabañas rurales/bungalós & 1 & 65 \\
\hline Total Alojamientos turísticos extrahotelero & 6 & 179 \\
\hline
\end{tabular}

Fuente: elaboración propia a partir de los portales consultados.

\section{Cuadro 4}

\section{INFRAESTRUCTURAS DE ALOJAMIENTO EXTRAHOTELERO EN EL AIS DEL PARQUE NACIONAL DE CABAÑEROS (2016)}

\begin{tabular}{|l|r|r|}
\hline & Total alojamientos & Total plazas \\
\hline CR alquiler completo (CA) & 42 & 425 \\
\hline CR alquiler compartido (AC) & 4 & 40 \\
\hline Apartamentos & 2 & 20 \\
\hline Camping/bungalows & 2 & 244 \\
\hline Cabañas rurales & 1 & 17 \\
\hline Complejo turístico/Vivienda turística & 2 & 20 \\
\hline Total Alojamientos turísticos (extrahotelero) & 53 & 866 \\
\hline
\end{tabular}

Fuente: elaboración propia a partir de los portales consultados.

El peso de las infraestructuras turísticas en Cabañeros es considerablemente mayor que en el caso anterior, sumando 53 alojamientos extrahoteleros en alguna de sus categorías frente a los seis alojamientos de similares características en Daimiel (cuadro 4). Del total de alojamientos, 42 se corresponden con casas rurales en régimen de alquiler completo; 
4 son casas rurales de alquiler compartido; 2 son apartamentos; 2 campings situados en Horcajo de los Montes y en Navas de Estena, unas cabañas rurales en Retuerta del Bullaque y dos viviendas turísticas. Sin duda, es el municipio de Retuerta de Bullaque el que concentra el mayor número de alojamientos (18 en total, 14 de ellos casas rurales) seguido de Los Navalucillos (10 casas rurales), Horcajo de los Montes (5 casas rurales, 1 camping y 1 apartamento) y Alcoba (7 casas rurales).

\subsection{Infraestructura de alojamiento hotelero}

Por lo que respecta a la infraestructura de alojamiento hotelero en el Parque Nacional de las Tablas de Daimiel, con un total de 10 alojamientos y 353 plazas (cuadro 5), destaca Daimiel con más de un $70 \%(71,3 \%)$ de las plazas con un hostal, tres hoteles y dos hoteles rurales. Le sigue Villarrubia de los Ojos con una pensión y un hostal que suman casi 70 plazas (19\% del total), y finalmente, el municipio de Torralba de Calatrava con dos hoteles (**) y un peso porcentual similar al de Villarrubia (68 plazas). La distribución de la oferta de plazas en esta categoría pone de manifiesto el papel de Daimiel en la comarca y su dinamismo económico y empresarial favorecido por su conectividad a la red de infraestructuras de comunicaciones.

\section{Cuadro 5 \\ INFRAESTRUCTURAS DE ALOJAMIENTOS HOTELEROS DEL ÁREA DE INFLUENCIA SOCIOECONÓMICA DEL PARQUE NACIONAL DE LAS TABLAS DE DAIMIEL (2016)}

\begin{tabular}{|l|r|r|}
\hline & Total alojamientos & Total plazas \\
\hline Pensión** & 1 & 7 \\
\hline Hostal $^{* *}$ & 2 & 84 \\
\hline Hotel $^{* *}$ & 3 & 94 \\
\hline Hotel*** & 2 & 114 \\
\hline Hotel rural & 2 & 54 \\
\hline Total Alojamientos & 10 & 353 \\
\hline
\end{tabular}

Fuente: elaboración propia a partir de los portales consultados.

La apuesta por el alojamiento incluido dentro del apartado de hospedaje tradicional en Cabañeros es mínima, con sólo 8 establecimientos clasificados dentro de este epígrafe (cuadro 6). De los cinco alojamientos en la categoría de hostal, dos de ellos se localizan en Horcajo de los Montes con más de 30 plazas; otro se encuentra en Alcoba de los Montes con 16 plazas; y otros dos en Retuerta del Bullaque, con más de 30 plazas. A este conjunto de alojamientos, se añadiría el único hotel de cuatro estrellas situado en Horcajo de los Montes, con 51 habitaciones, e inicialmente pensado para una clientela vinculada a las actividades cinegéticas y un hotel rural en el municipio de Retuerta del Bullaque con 10 plazas. 


\section{Cuadro 6}

INFRAESTRUCTURAS DE ALOJAMIENTO HOTELERO EN EL AIS DEL PARQUE NACIONAL DE CABAÑEROS (2016)

\begin{tabular}{|l|r|r|}
\hline & Total alojamientos & Total plazas \\
\hline Hostal $*$ & 5 & 83 \\
\hline Hostal $* *$ & 1 & 6 \\
\hline Hotel $* * * *$ & 1 & 90 \\
\hline Hotel rural & 1 & 10 \\
\hline Total Alojamientos & 8 & 189 \\
\hline
\end{tabular}

Fuente: elaboración propia a partir de los portales consultados.

El análisis de distribución espacial de la infraestructura de alojamientos extrahoteleros y hoteleros por municipios muestra importantes contrastes entre los mismos. Así, Retuerta del Bullaque cuenta con 22 de los 61 alojamientos (extra-hoteleros y hoteleros), lo que supone un 36,1\%; le sigue, Los Navalucillos con 12 alojamientos (19,7\%); Horcajo de los Montes con un $18 \%$ (11 alojamientos) y Alcoba con un 13,1\% (8 alojamientos). Las peores dotaciones de infraestructura de alojamiento se encuentran en Hontanar y Navas de Estena cada uno con tres y cinco establecimientos respectivamente. Por el contrario, si analizamos la infraestructura en función del número de plazas ofertadas (un total de 1.055 hoteleras y extrahoteleras), el $45 \%$ se concentra en Horcajo de los Montes ya que aglutina 475 plazas, 90 de ellas en el ya mencionado hotel de cuatro estrellas y 284 de un camping; seguido de Retuerta del Bullaque $(20,8 \%)$ con casi 220 plazas y Los Navalucillos con 149 plazas, todas ellas de carácter extrahotelero $(14,1 \%)$.

\subsection{Infraestructuras y servicios de restauración}

La oferta de establecimientos y servicios de restauración para el AIS Tablas de Daimiel se considera relativamente amplia. Encontramos casi sesenta restaurantes de diversa categoría (trece de 1 Tendedor, doce de 2 Tenedores y treinta y cuatro sin categoría específica) (cuadro 7). La localidad con mayor número es Daimiel con treinta y dos establecimientos (siete de $1 \mathrm{~T}$, seis de $2 \mathrm{~T}$, y diecinueve sin categoría específica) lo que supone un $54,2 \%$ sobre el total. Le sigue Villarrubia con veinte restaurantes (cuatro de $1 \mathrm{~T}$, cinco de $2 \mathrm{~T}$ y once sin categoría) que se traduce en un 33,9\% sobre el total. Y, finalmente, Torralba con siete restaurantes (uno de $1 \mathrm{~T}$, dos de $2 \mathrm{~T}$ y cuatro sin categoría), un $11,13 \%$ sobre el total.

En Cabañeros, la oferta de establecimientos y servicios destinados a la restauración se concentra básicamente en tres municipios (Horcajo de los Montes, Retuerta de Bullaque y Los Navalucillos) que, en total, suman 23 de los 33 restaurantes (un 69,7\% del total). Esta oferta es relativamente variada, ya que de los 33 restaurantes, 17 corresponden a la categoría 1 Tenedor, 6 de 2 Tenedores y 10 restaurantes sin categoría (cuadro 7). 


\section{Cuadro 7 \\ INFRAESTRUCTURAS DE RESTAURACIÓN EN EL ÁREA DE INFLUENCIA SOCIOECONÓMICA DEL PARQUE NACIONAL DE LAS TABLAS DE DAIMIEL Y PARQUE NACIONAL DE CABAÑEROS (2016)}

\begin{tabular}{|l|r|r|}
\hline & DAIMIEL & CABAÑEROS \\
\hline Restaurantes 1T & 13 & 17 \\
\hline Restaurantes 2T & 12 & 6 \\
\hline Restaurantes sin categoría & 34 & 10 \\
\hline Total Restaurantes & 59 & 33 \\
\hline
\end{tabular}

Fuente: elaboración propia a partir de los portales consultados.

En el extremo opuesto, los municipios con menos establecimientos de restauración, son Navas de Estena, con 4 restaurantes, Alcoba con tres establecimientos y Hontanar con 2.

\subsection{Establecimientos y servicios al turismo rural}

En este epígrafe hemos analizado las empresas que ofertan sus productos y servicios a una potencial demanda de turismo rural en el AIS: artesanía, productos típicos, senderismo, empresas de turismo activo, etc.

La artesanía del AIS del Parque Nacional de las Tablas de Daimiel es rica desde el punto de vista de la diversidad de las materias primas y de las técnicas utilizadas. En la comarca hemos localizado 18 establecimientos relacionados con la producción y venta de productos artesanales. Barro, fibras vegetales y cuero son los principales recursos naturales que se trabajan en los talleres artesanos de la comarca. En alfarería y cerámica destacan la cerámica elaborada a mano, la elaboración de vasijas, jarrones, botijos, palmatorias, candelabros, murales, azulejos, máscaras, bandejas, etc. que se producen en Daimiel y en Villarrubia. Otros productos de elaboración artesanal son: cestos, canastos, espejos, paneras, bolsos, cinturones, orfebrería manual y decorativa, etc.

Destacan las empresas y cooperativas dedicadas a la elaboración y comercialización de productos típicos (17) como vino, aceite, conservas, dulces, miel, jamón, carnes, etc. Los productos locales, apoyados por la presencia de varias D.O.P. e I.G.P., suponen un complemento de la economía de la comarca. Bodegas, queserías, sociedades cooperativas son algunos ejemplos de industrias agroalimentarias de la zona que se han ido especializando en vinos y quesos de calidad. Es de destacar la empresa Hermanos Jerez Moraleda, S.L. en Villarrubia de los Ojos, dedicada a la producción de vino ecológico.

$\mathrm{Y}$, finalmente, los equipamientos vinculados no sólo al turismo rural sino al turismo en su conjunto suman un total de 7 y entre ellos destacan especialmente los centros de interpretación, los museos y las oficinas de turismo. Algunas de las empresas destinadas al turismo activo, o al menos, las que apuestan por los destinos de naturaleza (Tablas de Daimiel u otro ENP de la comarca) como principal reclamo, se sitúan en los municipios del AIS (Brezotur, Turbycis, etc.) mientras que otras se afincan fuera del territorio propio utilizando el ENP como reclamo turístico para el desarrollo de sus actividades (cuadro 8). 


\section{Cuadro 8 \\ ESTABLECIMIENTOS EN EL ÁREA DE INFLUENCIA SOCIOECONÓMICA DEL PARQUE NACIONAL DE LAS TABLAS DE DAIMIEL (2016)}

\begin{tabular}{|r|c|c|}
\hline & DAIMIEL & CABAÑEROS \\
\hline Artesanía & 18 & 25 \\
\hline Elaboración y comercialización de productos típicos & 17 & 33 \\
\hline Servicios al turismo verde y activo & 13 & 16 \\
\hline Equipamiento turístico & 7 & 4 \\
\hline Total Establecimientos & 55 & 78 \\
\hline
\end{tabular}

Fuente: Elaboración propia a partir de los portales consultados.

En Cabañeros, y en relación con las empresas de productos típicos, dominan claramente los negocios vinculados a la elaboración y comercialización de leche y derivados, carne, aceite, etc. que mayoritariamente se concentran en Los Navalucillos, Horcajo de los Montes y Retuerta del Bullaque, siendo un reflejo de sus economías agroganaderas.

Respecto a la producción artesanal se puede decir que es limitada y fuertemente polarizada en la localidad de Los Navalucillos, donde domina básicamente la taxidermia vinculada a la actividad cinegética en la comarca y un establecimiento de elaboración de cerámica popular. En Horcajo de los Montes la producción artesana se centra en las alfombras y el trabajo de la madera y el corcho. A pesar de que estas empresas son las que menos empleo producen en la zona en datos absolutos, junto con las dedicadas al turismo activo (Caro, et al., 2009), su papel en la diversificación económica de la comarca no deja de ser relevante.

Las empresas dedicadas al turismo verde y activo apuestan por los destinos de naturaleza con el Parque Nacional de Cabañeros como principal reclamo y responden, debido a su implantación en el territorio, a la necesaria diversificación de la oferta (Troitiño Vinuesa, et al., 2006). Así, algunas de ellas tienen su sede en Horcajo de los Montes. Ahora bien, la mayoría están afincadas fuera de los límites del AIS realizando actividades de diverso tipo que se vinculan de alguna manera con este ENP aunque su campo de trabajo abarca otros ENP (Daimiel, Ruidera y complejos lagunares varios) desarrollando actividades propias de turismo activo. En contraste con esta proliferación, en los últimos años algunas empresas que ofrecían actividades similares en la comarca se han visto obligadas a cerrar (Caro, et al., 2009). Ello es síntoma de que parte del empresariado de la zona responde a un perfil de negocio familiar, con escasa profesionalización y capacidad de innovación, probablemente en relación con la escasa representación de población joven en esta comarca.

En el epígrafe de equipamientos, salvo Hontanar, el resto de municipios están representados con al menos una infraestructura. Destacan Horcajo de los Montes con un centro de visitantes y un museo etnográfico; Retuerta del Bullaque con otro museo y Alcoba que tiene el centro de interpretación Casa Palillos y un museo etnográfico. Oficina de turismo como tal sólo encontramos en Navas de Estena y un punto de información para la comarca de la Jara se sitúa en Los Navalucillos (cuadro 8). 
Antes de la declaración de este ENP el tipo de negocios y servicios que ofertaban el conjunto de municipios de la zona fundamentalmente satisfacía la demanda de un tipo de cliente que pasaba el verano en la comarca visitando parientes o amigos (estacional), y también de clientes relacionados con actividades comerciales (viajantes, transportistas, etc.) que se alojaban en los hostales de la zona, hostales que podían completar su ocupación durante los meses primaverales y sobre todo otoñales como consecuencia de las actividades cinegéticas. Hasta este momento la promoción turística de la comarca era escasa o prácticamente nula.

\section{CONCLUSIONES}

Sin duda, el turismo en espacios rurales se ha convertido en un elemento dinamizador de las rentas agrarias como se muestra especialmente en la comarca de Cabañeros. No hay que olvidar que la declaración de un ecosistema como ENP genera, prácticamente desde ese momento, un mayor volumen de visitantes atraídos por la etiqueta de calidad que supone esa nueva imagen de marca, haciéndolo reconocible y convirtiéndolo en un potencial destino ecoturístico (Pulido Fernández, 2008: 63-64). Esto provoca, generalmente, un incremento de la oferta y demanda de alojamientos y de servicios de restauración asociados no sólo a las proximidades del propio ENP sino también al conjunto del AIS e indirectamente a toda la comarca que se beneficia de la llegada de turistas al territorio.

En nuestro caso, nos encontramos ante dos comarcas y dos territorios con factores demográficos, sociales y económicos muy dispares en donde las actividades generadas por los ENP han supuesto un complemento cada vez más necesario de las rentas locales, especialmente en el territorio de Cabañeros con una economía predominante agroforestal; mientras que la comarca de Daimiel ha sufrido otro tipo de conflictos para sobrevivir como ecosistema protegido (presiones sobre el agua por parte de los intereses sociales y económicos del territorio).

El AIS de las Tablas de Daimiel cuenta con un gran número de recursos naturales y culturales de gran calidad y variedad. Sin embargo, aunque muchos de ellos se han recuperado y conservado, pocos se han convertido en elementos potenciales para su comercialización. La ruta de Don Quijote (Pillet Capdepón, 2011: 735), los Humedales y la ruta del Vino son los productos estrellas de la comarca a los que se añaden numerosos centros de interpretación, museos temáticos, fiestas populares de interés antropológico, conjuntos históricos y BICs. Sería necesario, desde nuestro punto de vista, seguir incentivando aquellas acciones destinadas a crear productos turísticos con el objetivo de mejorar, ampliar y diversificar la oferta existente.

El análisis de la oferta turística del AIS de las Tablas arroja una información interesante y muy distinta a la de Cabañeros. Por un lado, predomina el alojamiento hotelero más "tradicional" (hostales, hoteles, pensiones) y por otro lado, la oferta clásica tanto de alojamiento como de restauración se reparte entre dos municipios, Daimiel y Villarrubia, predominando en el primero la oferta de alojamiento hotelero y en el segundo la de restauración, municipio que ha aprovechado el tirón del Parque Nacional para abrir nuevos establecimientos. Empero, el sector de actividad que mayor crecimiento ha experimentado vinculado al turismo rural ha sido el de las empresas de turismo activo, dos radicadas en Daimiel y otra tercera que utiliza el ENP como principal recurso. 
El incremento de la oferta y la demanda de alojamientos y servicios de restauración en Cabañeros ha sido más evidente, y en algunos casos puede presentar un doble problema (Troitiño Vinuesa, et al., 2006: 257). Por un lado, la concentración espacial de las visitas y, por otro, la fuerte estacionalidad de las mismas, destacando los meses primaverales (abril y mayo) y los otoñales (septiembre y octubre), éstos últimos motivados por el fenómeno de la "berrea" en el Parque Nacional. Esto ha provocado la apuesta clara desde la dirección del Parque por la diversificación de la oferta y la modernización del servicio.

Con la declaración de Parque Nacional, el espacio recibe un marchamo de calidad que incrementa su notoriedad. El mismo Parque con sus subvenciones, añadidas a las procedentes de ayudas europeas, se convierte en un elemento de dinamización del territorio, a pesar de que la iniciativa local en territorios rurales como Cabañeros tiene dificultades a la hora de invertir y arriesgar prefiriendo en algunos casos el salario o subsidio agrario más "cómodo" de conseguir (Rodríguez Chumillas, et al., 2004), evitando los riesgos y complicaciones que supone emprender un negocio. Aún así, y según algunos autores (Caro, et al., 2009), desde la puesta en marcha del Parque Nacional éste habría sido el responsable de la creación de 316 empleos directos, entendiendo por tales aquellos desarrollados por una persona en jornada completa durante un año, de los cuales un $50 \%$ pertenece a personal que trabaja vinculado al Parque (guías, retenes, guardería, etc.), y un $37 \%$ a la rama de la restauración y hostelería, y más en concreto a alojamientos rurales de tipo extrahotelero (casas rurales, bungalós, campings...), frente al alojamiento hostelero más clásico, (hoteles y hostales) potenciado más en la comarca de Daimiel.

\section{BIBLIOGRAFÍA}

AA.VV. (1997a): Seminario sobre Alternativas de Desarrollo Económico para la población local de los Espacios Naturales Protegidos. Madrid, Fundación Fernando González Bernáldez.

AA.VV. (1997b): «Datos de interés», en Parque Nacional de Cabañeros. Madrid, Ecohábitat, pp. 403-411.

AA.VV. (2003): «Bonales, bohonales o trampales. Humedales poco conocidos», Revista Medio Ambiente Castilla-La Mancha, $\mathrm{n}^{\circ}$ 11, pp. 4-13.

AA.VV. (2009): «La Mancha Húmeda: Las Tablas de Daimiel», en Itinerarios geográficos y paisajes por la provincia de Ciudad Real. Ciudad Real, Diputación de Ciudad Real, pp. 71-88.

ALBA ALONSO, J. y RIVAS, D. (1996): «El turismo en los espacios naturales protegidos: Consideraciones generales y análisis del Parque de Somiedo», en Turismo y promoción de destinos turísticos: implicaciones empresariales. Oviedo, Universidad de Oviedo.

ANTÓN ClAVÉ, S., BLAY BOQUÉ, J., y SALVAT SALVAT, J. (2008): «Turismo, actividades recreativas y uso público en los parques naturales. Propuesta para la conservación de los valores ambientales y el desarrollo productivo local», Boletín de la Asociación de Geógrafos Españoles, n ${ }^{\circ}$ 58, pp. 5-38.

BLANCO PORTILLO, R. (2005): «Diseño de un producto de ecoturismo en parques acreditados con la Carta Europea del Turismo Sostenible (CETS)», en XI Congreso EUROPARC-España. ESPARC 2005. Comunicar los beneficios de los espacios protegidos a la sociedad. Madrid, Fundación Fernando González Bernáldez, pp. 18-25. 
CABALLERO KLINK, A. (1997): «Arqueología», en Parque Nacional de Cabañeros. Madrid, Ecohábitat, pp. 269-278.

CAÑIZARES RUIZ, M.C. (2008): «La "Ruta de Don Quijote" en Castilla-La Mancha (España): nuevo itinerario cultural europeo», Nimbus, n 21-22, pp. 55-75.

CARO HIDALGO, J., DÍAZ HERNÁNDEZ, S., SUNYER LACHIONDO, C. y VIÑUELA MADERA, J. (2009): «Contribución del Parque Nacional de Cabañeros al Desarrollo Rural del entorno», en Eco-emprendedores: Retos para la puesta en valor de los espacios protegidos. Madrid, Terracentro, pp. 23-30.

CARRASCO REDONDO, M. (2001): Guía de visita del Parque Nacional de las Tablas de Daimiel. Madrid, Organismo Autónomo Parques Nacionales. Ministerio de Medio Ambiente.

CORONADO CASTILLO, R., LEÓN JIMÉNEZ, F. y MORILLO FERNÁNDEZ, C. (1974): Guía del Parque Nacional de las Tablas de Daimiel. Madrid, ICONA.

DE LA BELDAD CARO, A., SERRANO MENCHÉN, P. y BENÍTEZ DE LUGO ENRICH, L. (2007): Comarca Entreparques: Tablas de Daimiel, Cabañeros, Lagunas de Ruidera y Alarcos. Barcelona, Alhena Media.

DE LA ROSA GUILLÓN, C. (2005): «La Carta Europea del Turismo Sostenible en Espacios Naturales Protegidos», en XI Congreso EUROPARC-España. ESPARC 2005. Comunicar los beneficios de los espacios protegidos a la sociedad.

EUROPARC-ESPAÑA (2002): Plan de Acción para los espacios naturales protegidos del Estado Español. Madrid, Fundación Fernando González Bernáldez.

FERNÁNDEZ TABALES, A. y SANTOS PAVÓN, E.L. (2010): «Turismo y parques naturales en Andalucía tras veinte años desde su declaración. Análisis estadístico, tipología de parques y problemática de la situación actual», Anales de Geografía de la Universidad Complutense, vol. 30, nº 1, pp. 29-54.

HERAS FERNÁNDEZ, F. (2001): «La participación en la planificación y gestión de los espacios naturales protegidos», en Plan de acción para los espacios naturales del estado español. Madrid, Fundación Fernando González Bernáldez.

JEREZ GARCÍA, Ó. (2010): La Reserva de la Biosfera de La Mancha Húmeda y la Cuenca Alta del Guadiana. Guía Didáctica del medio físico y la evolución de los paisajes. Ciudad Real, Universidad de Castilla-La Mancha.

MUÑOZ FLORES, J.C. (2008): «El turismo en los espacios naturales protegidos españoles, algo más que una moda reciente», Boletín de la Asociación de Geógrafos Españoles, n. 46, pp. 291-304.

PEINADO MARTÍN-MONTALVO, M. y PLAZA TABASCO, J. (2011): «La Reserva de la Biosfera y La Mancha: geografía, territorio y paisaje», en Reserva de la Biosfera de La Mancha Húmeda. Madrid, pp. 43-51.

PILLET CAPDEPÓN, F. (2011): «El turismo de interior y el patrimonio territorial en Castilla-La Mancha», Cuadernos de Turismo, n. 27, pp. 725-741.

PRATS SANTAFLORENTINA, J. M. (2005): «El valor de la Carta Europea para el conjunto de la gestión de los parques», en XI Congreso EUROPARC-España. ESPARC 2005. Comunicar los beneficios de los espacios protegidos a la sociedad, Madrid, Fundación Fernando González Bernáldez, pp. 9-13. 
PUERTAS CAÑAVERAL, I. (2008): Ecoturismo en las reservas de la Biosfera. Granada, Universidad de Granada.

PULIDO FERNÁNDEZ, J.I. (2007a): «El turismo en el desarrollo económico de los parques naturales andaluces. Un análisis Delphi de los principales déficit», Revista de Estudios Empresariales, $\mathrm{n}^{\circ}$ 1, pp. 110-137.

PULIDO FERNÁNDEZ, J.I. (2007b): «Elementos para orientar la formulación de una política turística sostenible en los parques naturales andaluces», Cuadernos de Turismo, $\mathrm{n}^{\circ} 19$, pp. 167-188.

PULIDO FERNÁNDEZ, J. I. (2008): «Los parques naturales como productos turísticos. Estudios de caso», en Ofertas no turismo rural: elaboración e promoción. Vigo, Universidad de Vigo, pp. 51-78.

RODRÍGUEZ CHUMILLAS, I., DE LA TORRE MARCOS, D. J. y GIL RODRÍGUEZ, C. (2004): «Empleo femenino y turismo rural: una investigación aplicada al caso de Cabañeros», en Mujeres, medio ambiente y desarrollo rural. Madrid, Instituto Universitario de Estudios de la Mujer, Universidad Autónoma de Madrid, pp. 219-228.

RODRÍGUEZ JIMÉNEZ, J. L. (1986): Castilla La Mancha. Guía de la naturaleza. León, Editorial Everest.

RUIZ PULPÓN, Á.R., SERRANO DE LA CRUZ M.A. y JEREZ, Ó. (2010): «Repercusiones de las políticas públicas en la transformación de espacios de alto valor ambiental: contradicciones en La Mancha Húmeda», en Las escalas de la Geografía: del mundo al lugar. Homenaje al profesor Miguel Panadero Moya. Cuenca, Servicio de Publicaciones de la Universidad de Castilla-La Mancha, pp. 303-328.

SERRANO DE LA CRUZ SANTOS-OLMO, M.A. (2002): «Aproximación a un ejemplo de presión turística en un espacio natural protegido: el parque natural de las Lagunas de Ruidera», en Turismo y transformaciones urbanas en el siglo XXI. Almería, Universidad de Almería, pp. 345-356.

TOLÓN BECERRA,A., (2000): «Espacios naturales protegidos. Desarrollo rural y socioeconómico», Agricultura: Revista agropecuaria, nº 813, pp. 166-170.

TROITIÑO VIÑUESA, M.Á. (1995): «Espacios naturales protegidos y desarrollo rural: una relación territorial conflictiva», Boletín de la Asociación de Geógrafos Españoles, $\mathrm{n}^{\mathrm{o}} 20$, pp. 7-37.

TROITIÑO VINUESA, M.Á., DE MARCOS, F.J., DÍAZ, E.O., ABAD, L.D., DEL RÍO, M. I., GARCÍA, M., DE LA CALLE VAQUERO, M. y CARPIO MARTÍN, J. (2006): «El Parque Nacional de Cabañeros: encuentros y desencuentros en la gestión de un territorio de ruralidad profunda», en Gobernanza territorial en España: claroscuros de un proceso a partir del estudio de casos. Valencia, Universidad de Valencia, pp. 245-270.

VALENZUELA RUBIO, M. (1997): Los turismos de interior. El retorno a la tradición viajera. Madrid, Asociación de Geógrafos Españoles y Universidad Autónoma de Madrid.

\section{FUENTES}

CONSEJERÍA DE INDUSTRIA, ENERGÍA y MEDIO AMBIENTE DE LA JUNTA DE COMUNIDADES DE CASTILLA-LA MANCHA (2005): Decreto 77/2005, de 28 de junio, de Ordenación de las Empresas de Turismo Activo de Castilla-La Mancha. 
JEFATURA DEL ESTADO (1982): Real Decreto 1105/1982, de 14 mayo, actuación del ICONA en las zonas de influencia socio-económica.

JEFATURA DEL ESTADO (1995): Ley 33/1995, de 20 de noviembre, de declaración del Parque Nacional de Cabañeros.

MINISTERIO DE MEDIO AMBIENTE, MEDIO RURAL y MARINO (2008a): «Resumen ejecutivo», en Primer informe de situación de la Red de Parques Nacionales.

MINISTERIO DE MEDIO AMBIENTE, MEDIO RURAL y MARINO (2008b): «Parque Nacional de Cabañeros: Indicadores de estado y gestión», en Primer informe de situación de la Red de Parques Nacionales.

MINISTERIO DE AGRICULTURA, ALIMENTACIÓN y MEDIO AMBIENTE (2010, 2011, 2012): Memoria de la Red de Parques Nacionales. Organismo Autónomo de Parques Nacionales.

MINISTERIO DE AGRICULTURA, ALIMENTACIÓN y MEDIO AMBIENTE (2014a): Resolución de 21 de enero de 2014, de Parques Nacionales, por la que se publica el Acuerdo del Consejo de Ministros de 10 de enero de 2014 por el que se amplían los límites del Parque Nacional de las Tablas de Daimiel por incorporación de terrenos colindantes al mismo.

MINISTERIO DE AGRICULTURA, ALIMENTACIÓN y MEDIO AMBIENTE (2014b): Resolución de 17 de noviembre de 2014, de Parques Nacionales, por la que se publica la aprobación por la UNESCO de la ampliación de la Reserva de la Biosfera de Montseny, Cataluña, y la Reserva de la Biosfera de La Mancha Húmeda, en CastillaLa Mancha. 